\title{
Four Element Microstrip Antenna Array with Electromagnetic Band Gap Structure and Silver Material Deposition for Reduced Mutual Coupling
}

\author{
K. Prahlada Rao ${ }^{1 *}$, Vani R.M ${ }^{2}$, P.V. Hunagund ${ }^{1}$ \\ ${ }^{1}$ Gulbarga University, \\ Dept. of PG Studies \& Research in Applied Electronics, Gulbarga University, Gulbarga, 585106, INDIA \\ ${ }^{2}$ Gulbarga University, \\ University Science Instrumentation Centre, Gulbarga University, Gulbarga, 585106, INDIA \\ *Corresponding Author
}

DOI: https://doi.org/10.30880/jst.2019.11.01.002

Received 20 February 2019; Accepted 3 June 2019; Available online 15 June 2019

\begin{abstract}
This paper presents the performance of four element microstrip antenna array. The overall bandwidth of the microstrip antenna array with silver material coating is equal to $228.53 \%$ as compared to $75.91 \%$ without silver material coating. The microstrip antenna array with silver material coating of $30 \mathrm{~mm}$ thickness is producing good reduction in mutual coupling values at the resonant frequency of $5.53 \mathrm{GHz}$. Moreover, the radiation properties of antenna array are improved with good reduction in power radiated in the undesired direction. FR-4 glass epoxy substrate is used as dielectric substrate which has a dielectric constant of 4.2 and loss tangent of 0.0245. The microstrip antenna arrays are designed using Mentor Graphics IE3D software and the measured results are obtained using vector network analyzer.
\end{abstract}

Keyword: Four element, Microstrip antenna array, Electromagnetic Band Gap, Silver.

\section{Introduction}

In antenna theory and analysis a short electric current carrying element is considered as the basic antenna. Progress in science and technology has been a propelling force for the design and development of new and efficient antennas. In recent years microstrip antennas and arrays have become new direction of research in antenna engineering. A microstrip antenna is made up of a dielectric substrate sandwiched between the ground planes and radiating patch. These antennas have fascinated scientists because of their advantages like less weight, planar structure, ease of fabrication and compatibility with other devices. However, these antennas suffer from narrow bandwidth and high level of interference. One of the methods that provide substantial solution to the disadvantages of microstrip antennas and arrays is Electromagnetic Band Gap (EBG) structures. [1-3].

EBG structures are defined as manmade periodic structures that prevent or stop the propagation of electromagnetic waves for a particular band of frequencies for all incident angles and polarization states. EBG structures can be dielectric materials or metallic conductors. Generally EBG structures are categorized into three types: three dimensional, two dimensional and one dimensional. The two dimensional and one dimensional structures are preferred over the three dimensional structures as the three dimensional structures are complicated to design and implement. [4].

In [5] authors have discussed the study of EBG structures loaded in the ground plane, their types, and their behaviour in enhancing the performance of two element microstrip patch antenna arrays. The EBG structures employed 
are of two dimensional in nature and corporate feeding technique is used to feed the antenna arrays. The performances of square, circular, star, H and I shape EBG structures are compared. Highest bandwidth of $5.1 \%$ has been achieved using $\mathrm{H}$ shape EBG structure. Least amount of mutual coupling of $-30 \mathrm{~dB}$ and highest gain of $13.75 \mathrm{~dB}$ have been obtained in the case of star shape EBG structure. In [6] authors have designed a miniaturized patch antenna array resonating at 5.8 GHz WLAN band. The novel mushroom like EBG structure is loaded in between the patches. The dimensions of the patches are $14 \mathrm{~mm} \times 11.4 \mathrm{~mm}$ and the two patches are separated by $30 \mathrm{~mm}$. Initially, the mutual coupling between the antenna elements is $-19.97 \mathrm{~dB}$. As the distance of separation is decreased, mutual coupling is increased and vice versa. After the introduction of array of 3 rows and 2 columns of EBG structure on the structure, the mutual coupling is equal to $-35 \mathrm{~dB}$. Using other methods like substrate removal and back cavity, the mutual coupling values are higher than that produced by EBG structure equal to -20 and $-21 \mathrm{~dB}$ respectively. In [7] authors have designed novel single and two elements KSA (kingdom of Saudi Arabia) sign shape slot microstrip antennas with KSA shape EBG embedded on the surface and in between them. In the case of single element antenna, ultra wide band of 7.7 $\mathrm{GHz}(2.3-10 \mathrm{GHz})$ is obtained. Gains of 2.9 and $4.6 \mathrm{~dB}$ are obtained at the two resonant frequencies $2.8 \mathrm{and} 8.6 \mathrm{GHz}$ respectively. High amount of radiation and antenna efficiencies of 94, 87, 93 and $84 \%$ are obtained. In the case of two element antenna array, bandwidths of 37 and $58 \%$ are obtained at the two resonant frequencies 2.8 and $8.6 \mathrm{GHz}$ respectively. Enhanced gains of 3.2 and $5.5 \mathrm{~dB}$ are obtained at the corresponding resonant frequencies. Mutual coupling is reduced from -11.5 and -13.2 to -14.6 and $-20.2 \mathrm{~dB}$ respectively at the two resonant frequencies. Radiation and antenna efficiencies are increased to 98, 78, 95 and $77 \%$ respectively. The designed antennas are employed in soldier belts for military applications. In [8] authors have compared the performance of different types of EBG structures for single and dual bands. For single band operation, swastika type EBG structure is exhibiting the best performance in terms of bandwidth and compactness. Highest bandwidth of $3.6 \mathrm{GHz}$ is obtained. The other EBG structures cross hair and hexagonal patch are producing bandwidths of 2.28 and $1.67 \mathrm{GHz}$ respectively. Among the dual band EBG structures, fractal EBG is producing highest bandwidth of $3.69 \mathrm{GHz}$. Bandwidths produced by hexagonal patch with double $\mathrm{C}$ type slot and square patch with single discontinued loop type slot EBG structures are 2.03 and $1.97 \mathrm{GHz}$ respectively. In terms of compactness, square patch with single discontinued loop type slot EBG structure is the best candidate. In [9] authors have designed an aperture coupled stacked microstrip antenna array using mushroom like EBG structure. Initially single element antenna is designed and simulated. Impedance bandwidth and gain of $2 \mathrm{GHz}$ and above $6.8 \mathrm{~dB}$ are obtained. Later two element antenna array is designed with spacing between the antenna elements as $\lambda / 2$. The value of mutual coupling is varying between -13 to $-15 \mathrm{~dB}$. There is a drop in the gain to $5.6 \mathrm{~dB}$. The radius of the via and spacing between the adjacent unit cells of the mushroom EBG are 0.5 and $0.2 \mathrm{~mm}$ respectively. Using one, two and three rows of $\mathrm{EBG}$, the value of mutual coupling is reduced by 3,8 and $10 \mathrm{~dB}$ respectively. In [10] authors have analyzed the performance of $2 \times 2$ microstrip antenna array using EBG structure. Each cell of EBG structure has T and L shaped slots. The EBG structure is placed on the surface and in between the radiating patches. In the presence of EBG structure the bandwidth and gain are enhanced to $5.1 \mathrm{GHz}$ and $11.76 \mathrm{~dB}$ respectively. Appreciable reduction in mutual coupling coefficients is also produced. In [11] authors have examined the performance of microstrip antenna integrated phased array using $2 \times 5$ matrix of mushroom like EBG structure with a band gap centred at $5.8 \mathrm{GHz}$. The two antenna elements are separated by $30 \mathrm{~mm}$. The EBG structure is placed on the surface and in between the two radiating elements. The EBG structure has a band gap of 4.5 to $7 \mathrm{GHz}$, where it can suppress the unwanted surface waves. In the presence of EBG structure, the mutual coupling is brought down from -21 to $-47.23 \mathrm{~dB}$. In [12] authors have discussed the different techniques employed for mutual coupling reduction in microstrip antenna arrays. These are using EBG structures, split ring resonators, EBG - split ring resonators and defective ground structures. Using EBG and split ring resonator between two radiating elements, reduces the mutual coupling more compared to other techniques. The mutual coupling is reduced to more than $42 \mathrm{~dB}$ and side lobes by 6 $\mathrm{dB}$. The proposed antenna with spiral resonator has $5.5 \mathrm{~dB}$ reduction in mutual coupling. A $36 \mathrm{~dB}$ reduction in mutual coupling is achieved using defective ground structure. In [13] authors have examined the effect of slots on the rectangular radiating patch and rectangular DGS. The four element antenna array is found to resonate at 1.8 and 2.4 $\mathrm{GHz}$ with return losses -32 and $-30 \mathrm{~dB}$. Increasing the ground size width increases the return loss. Additionally, increasing the feed with increases the bandwidth and decreases the return loss. The designed antenna array is useful for WiMax and WLAN applications. In [14] authors have designed two pairs of microstrip antennas on Roger RT/Duroid 6010 substrate. In the presence of EBG structure with small number of holes (diameter of the holes is $1.27 \mathrm{~cm}$ ), the mutual coupling is reduced from -16.8 to $-18.9 \mathrm{~dB}$. With middle holes with dielectric constant 5.6 and 10.6 , no improvement in mutual coupling is observed using different feeding techniques. Using large number of holes, 1 and 2 $\mathrm{dB}$ reduction in mutual coupling is obtained. Later three and five columns of mushroom like EBG patches are inserted between the antenna elements. The size of the EBG patch is $3 \mathrm{~mm}$ and the gap between the patches is $0.5 \mathrm{~mm}$. The mutual coupling in the presence of mushroom like EBG patch is reduced to -19.8 and $-23.5 \mathrm{~dB}$. With two, four and six columns, the mutual coupling is reduced to $-19.2,-22.5$ and $-23.5 \mathrm{~dB}$ respectively. In [15] authors have designed dual band MIMO antenna system with enhanced isolation. Using a double rectangular DGS, the antenna is resonating at 2.6 and $5.7 \mathrm{GHz}$ with bandwidths of 5.7 and $4.3 \%$ respectively. The proposed antenna is having high isolation which is stable and around $-20 \mathrm{~dB}$ over all frequencies. At $2.6 \mathrm{GHz}$, gain and radiation efficiency are $2.63 \mathrm{~dB}$ and $59 \%$. The corresponding values at $5.7 \mathrm{GHz}$ are $1.6 \mathrm{~dB}$ and $39.8 \%$. MIMO antenna with double side EBG structure is reducing 
mutual coupling from -20 to $-40 \mathrm{~dB}$. At $2.6 \mathrm{GHz}$ the antenna gain and radiation efficiency are improved to $4.25 \mathrm{~dB}$ and $68.7 \%$. At $5.7 \mathrm{GHz}$, the antenna gain is increased to $1.76 \mathrm{~dB}$ and radiation efficiency to $39.8 \%$.

\section{Design of Conventional Microstrip Antenna Array}

The conventional microstrip antenna array (CMAA) consists of four radiating patches fed by corporate feeding technique as depicted in Fig. 1. The CMAA is designed at the frequency of $6 \mathrm{GHz}$. All the four radiating patches are identical in shape and dimensions. The distance between the two adjacent antenna elements is equal to $\lambda / 4$, where $\lambda$ is the wavelength calculated at the design frequency of $6 \mathrm{GHz}$. Each of the rectangular radiating patch or element has dimensions equal to $15.73 \mathrm{~mm} \times 11.76 \mathrm{~mm}$. The length and width of the quarter wave transformer are 6.47 and 0.47 $\mathrm{mm}$ respectively. The feeding element is in the form of $50 \Omega$ transmission line whose dimensions are $6.52 \mathrm{~mm} \times 3.05$ mm respectively. 70 and $100 \Omega$ transmission lines are also employed in the design process. All the other dimensions of CMAA are summarized in Table 1.

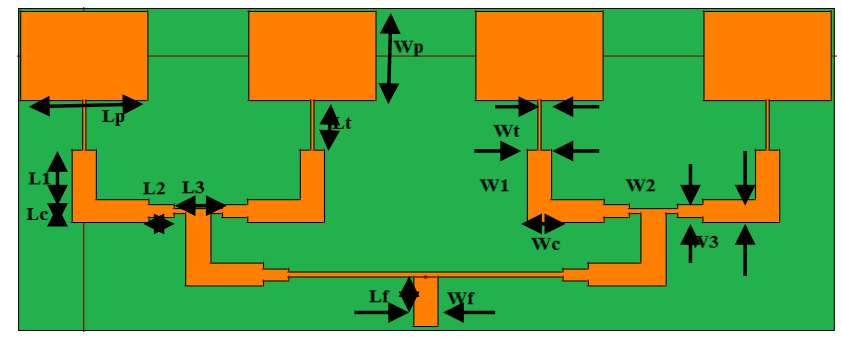

Fig. 1 - Schematic of CMAA.

Table 1 - Parameter values of CMAA.

\begin{tabular}{|l|c|}
\hline Parameter & Value $(\mathbf{m m})$ \\
\hline Length of the Patch $\left(\mathrm{L}_{\mathrm{p}}\right)$ & 15.73 \\
Width of the Patch $\left(\mathrm{W}_{\mathrm{p}}\right)$ & 11.76 \\
Length of the quarter wave transformer $\left(\mathrm{L}_{\mathrm{t}}\right)$ & 6.47 \\
Width of the quarter wave transformer $\left(\mathrm{W}_{\mathrm{t}}\right)$ & 0.47 \\
Length of the $50 \Omega$ line $\left(\mathrm{L}_{1}\right)$ & 6.52 \\
Width of the $50 \Omega$ line $\left(\mathrm{W}_{1}\right)$ & 3.05 \\
Length of the coupler $\left(\mathrm{L}_{\mathrm{c}}\right)$ & 3.05 \\
Width of the coupler $\left(\mathrm{W}_{\mathrm{c}}\right)$ & 3.05 \\
Length of the $70 \Omega$ line $\left(\mathrm{L}_{2}\right)$ & 6.54 \\
Width of the $70 \Omega$ line $\left(\mathrm{W}_{2}\right)$ & 1.62 \\
Length of the $100 \Omega$ line $\left(\mathrm{L}_{3}\right)$ & 6.56 \\
Width of the $100 \Omega$ line $\left(\mathrm{W}_{3}\right)$ & 0.70 \\
Length of the $100 \Omega$ line $\left(\mathrm{L}_{3}\right)$ & 6.52 \\
Width of the $100 \Omega$ line $\left(\mathrm{W}_{3}\right)$ & 3.05 \\
\hline
\end{tabular}

To study the performance of CMAA in terms of the mutual coupling parameter, all the four antenna elements are excited individually as shown in Fig. 2. The distance between the adjacent antenna elements is maintained the same as that in Fig. 1. The antenna elements are assumed to be fed with the same amount of power.

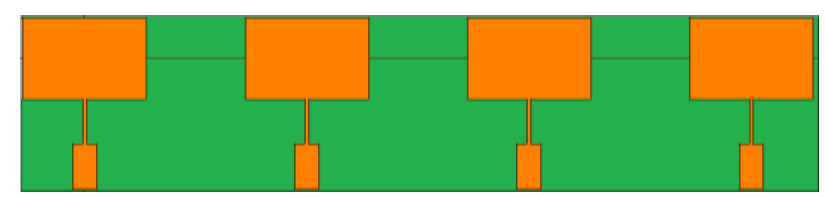

Fig. 2 - Schematic of arrangement of CMAA for mutual coupling measurement. 


\section{Design of Proposed Microstrip Antenna Arrays}

The design of proposed microstrip antenna array 1 involves the replacement of finite ground of CMAA with fork shape slot type EBG structure. The unit cell of fork shape slot type EBG structures is depicted in Fig. 3.

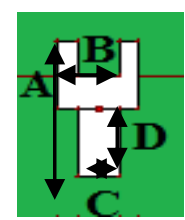

Fig. 3 - Schematic of unit cell of fork shape slot type EBG structure

In Fig. $3 \mathrm{~A}=10 \mathrm{~mm}, \mathrm{~B}=2.5 \mathrm{~mm}, \mathrm{C}=2 \mathrm{~mm}, \mathrm{D}=5 \mathrm{~mm}, \mathrm{M}=5 \mathrm{~mm}$ and $\mathrm{N}=4 \mathrm{~mm}$ respectively. The schematic of EBG structure employed in the design of proposed microstrip antenna array 1 is shown in Fig. 4.

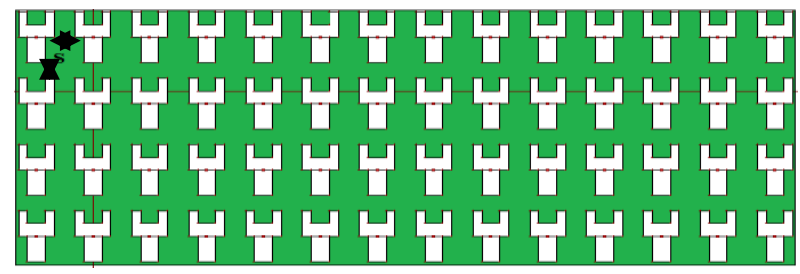

Fig. 4 - Schematic of fork shape slot type EBG structure.

Fig. 4 consists of a matrix of 14 columns and 4 rows of fork shape slot type unit cells. In Fig. 4, the periodicity of the cells of the EBG structure is equal to $\mathrm{G}=5 \mathrm{~mm}$. The proposed microstrip antenna array 1 is obtained by embedding the EBG structure shown in Fig. 4 in the ground plane of CMAA. The schematic of the proposed microstrip antenna array 1 is shown in Fig. 5.

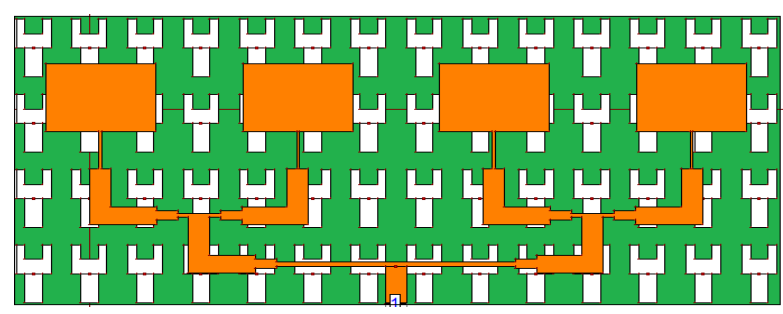

Fig. 5 - Schematic of proposed microstrip antenna array 1.

In order to examine the effect of fractal slot type EBG structure on the mutual coupling parameter, the fractal slot type EBG structure is integrated in the finite ground plane of schematic shown in Fig. 2. Fig. 6 depicts the arrangement of proposed microstrip antenna array 1 to determine the variation in mutual coupling.

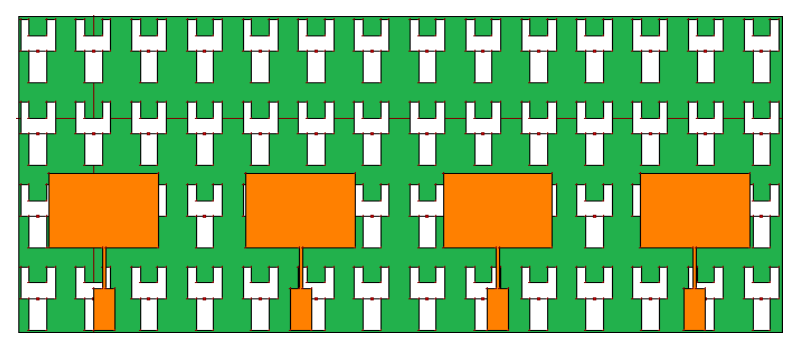

Fig. 6 - Schematic of arrangement of proposed microstrip antenna array 1 for mutual coupling measurement. 
Proposed microstrip antenna array 2 is obtained by modifying the surface of proposed microstrip antenna array 1 . The ground plane of proposed microstrip antenna array 2 is same as that of proposed microstrip antenna array 1 . The surface of proposed microstrip antenna array 2 has U shape patch type EBG structure loaded in between the individual radiating patches. The schematics of unit cell and EBG structure of U shape patch type EBG structure are depicted in Fig. 7 and 8. In Fig. 7, $\mathrm{M}=5 \mathrm{~mm}$ and $\mathrm{N}=4 \mathrm{~mm}$ respectively.

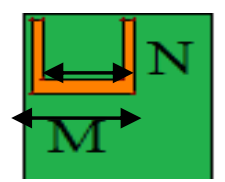

Fig. 7 - Schematic of unit cell of U shape patch type EBG structure.

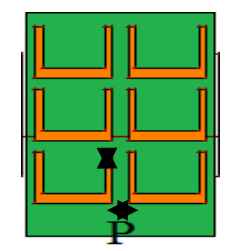

Fig. 8 - Schematic of U shape slot type EBG structure.

The schematic depicted in Fig. 8 is a matrix of 2 columns and 3 rows of $U$ shape patch type unit cells. The periodicity of unit cells in Fig. 8 is $\mathrm{P}=1 \mathrm{~mm}$. The schematic of proposed microstrip antenna array 2 is shown in Fig. 9.

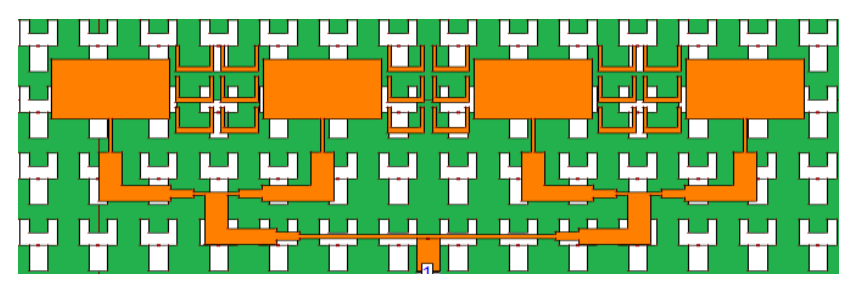

Fig. 9 - Schematic of proposed microstrip antenna array 2. 2.

The schematic shown in Fig. 10 is employed to measure the mutual coupling of proposed microstrip antenna array

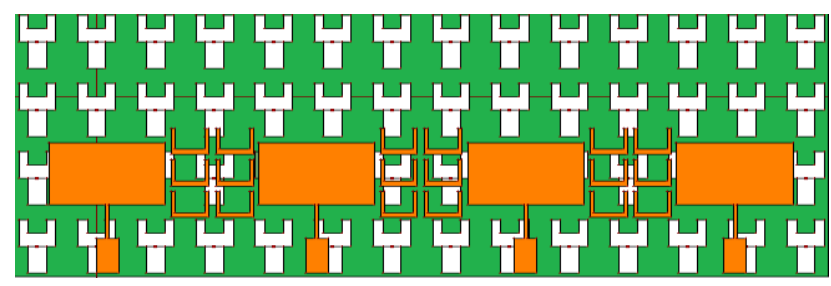

Fig. 10 - Schematic of arrangement of proposed microstrip antenna array 2 for mutual coupling measurement.

Silver material coating of thickness $30 \mathrm{~nm}$ is deposited on the entire copper area of proposed microstrip antenna array 2 to design the proposed microstrip antenna array 3. Fig. 11 depicts the schematic of proposed microstrip antenna array 3 . 


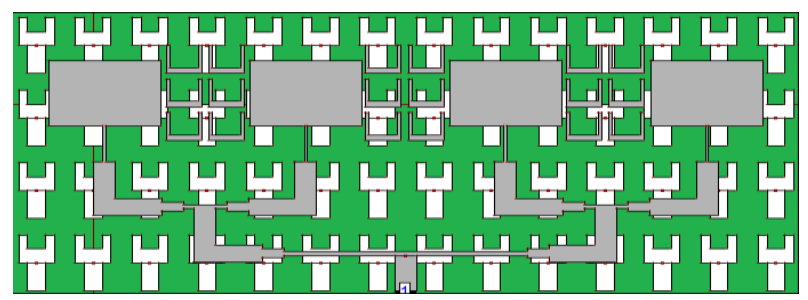

Fig. 11 - Schematic of proposed microstrip antenna array 3.

Fig. 12 shows the schematic used to determine the mutual coupling of proposed microstrip antenna array 3. In Fig. 11 and 12 the grey colour indicates the silver material deposition.

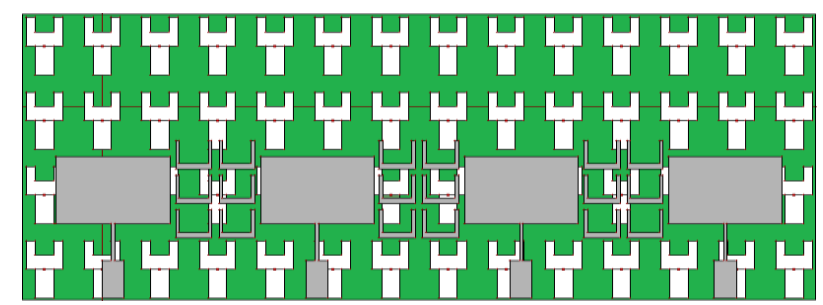

Fig. 12 - Schematic of arrangement of proposed microstrip antenna array 3 for mutual coupling measurement.

Fig. 13, 14, 15, 16, 17, 18, 19 and 20 depict the photographs of the fabricated microstrip antenna arrays.

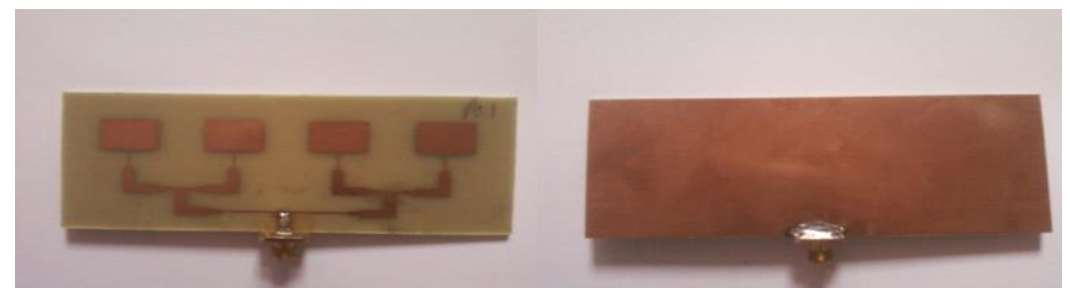

Fig. 13 - Photograph of CMAA. (a) Front view; (b) Back view

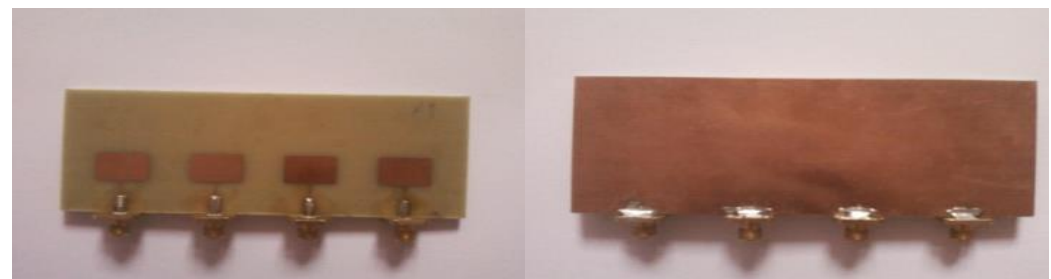

Fig. 14 - Photograph of CMAA arrangement for mutual coupling measurement (a) Front view; (b) Back view

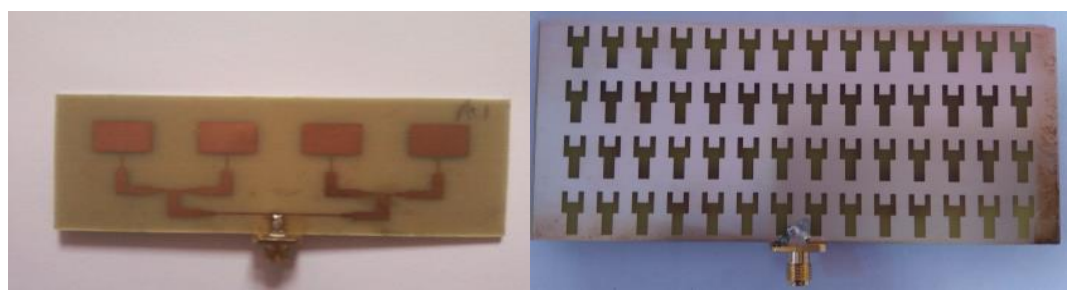

Fig. 15 - Photograph of Proposed Microstrip Antenna Array 1. (a) Front view; (b) Back view 


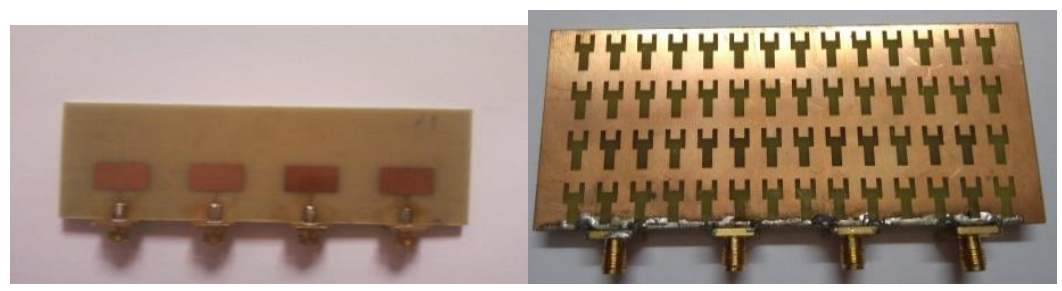

Fig. 16 - Photograph of Proposed Microstrip Antenna Array 1 arrangement for mutual coupling measurement (a) Front view; (b) Back view
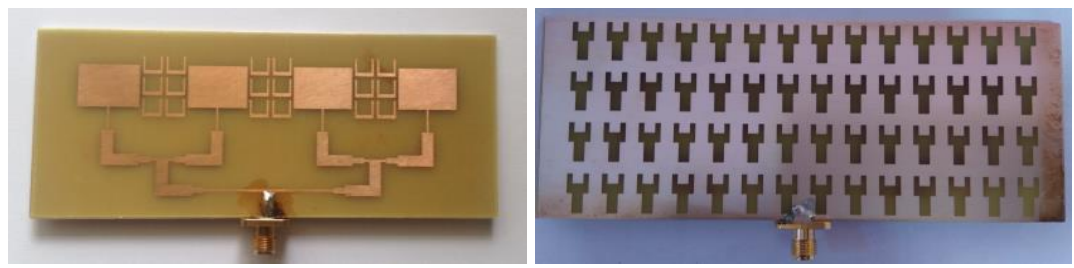

Fig. 17 - Photograph of Proposed Microstrip Antenna Array 2. (a) Front view; (b) Back view

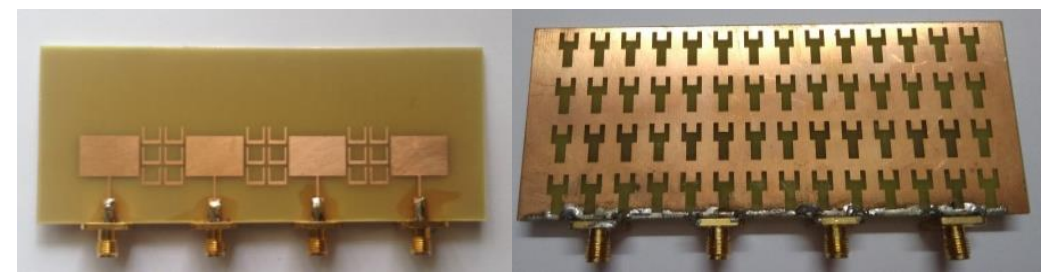

Fig. 18 - Photograph of Proposed Microstrip Antenna Array 2 arrangement for mutual coupling measurement (a) Front view; (b) Back view

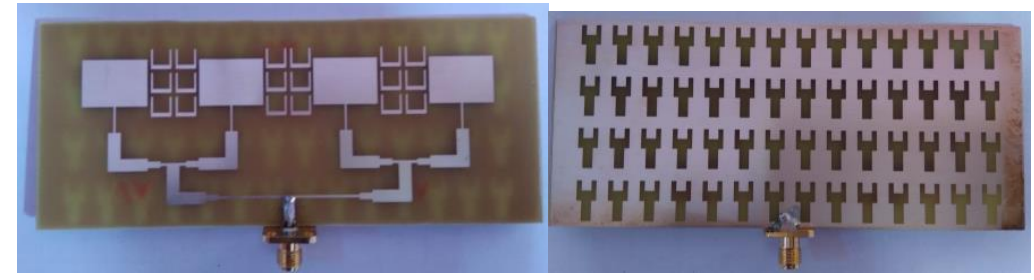

Fig. 19 - Photograph of Proposed Microstrip Antenna Array 3. (a) Front view; (b) Back view

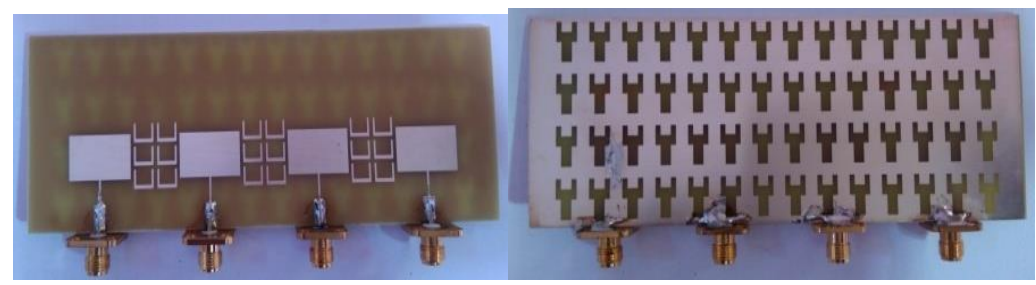

Fig. 20 - Photograph of Proposed Microstrip Antenna Array 3 arrangement for mutual coupling measurement (a) Front view; (b) Back view

The single feeding line does not contribute to mutual coupling because for the measurement of mutual coupling one port has to act as input port and the other as output port. Mutual coupling is nothing but the transmission coefficients.

\section{Results and Discussion}

The measured results of CMAA, proposed microstrip antenna arrays 1,2 and 3 are obtained using vector network analyzer. Various parameters like return loss, bandwidth (\%), mutual coupling, forward power, back lobe radiation, front to back ratio (FBR) and virtual size reduction $(\%)$ are determined and compared for the conventional and proposed microstrip antenna arrays. 
The mutual coupling parameters $-S_{21}, S_{31}$ and $S_{41}$ are measured. The graphs of return loss and mutual coupling versus frequency of CMAA are depicted in Fig. 21, 22 and 23 respectively.

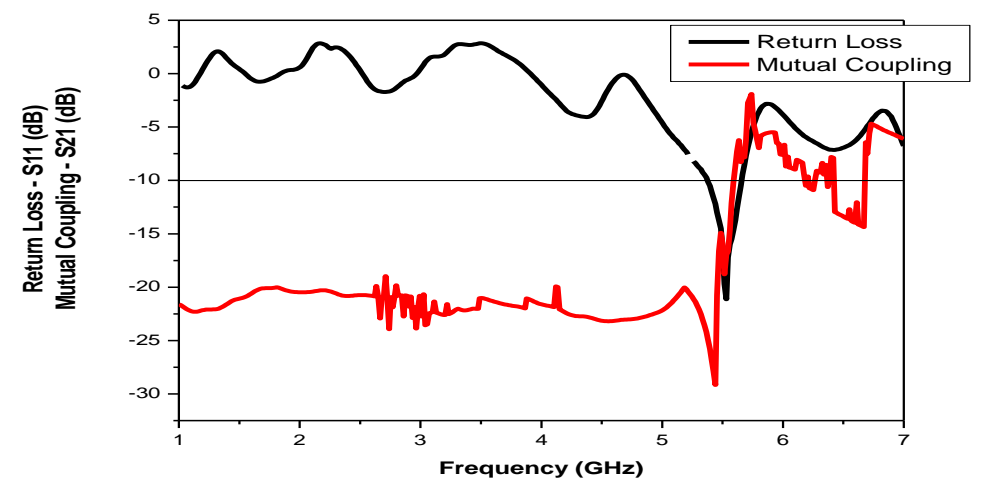

Fig. 21 - Graph of Return Loss and Mutual Coupling - S21versus Frequency of CMAA.

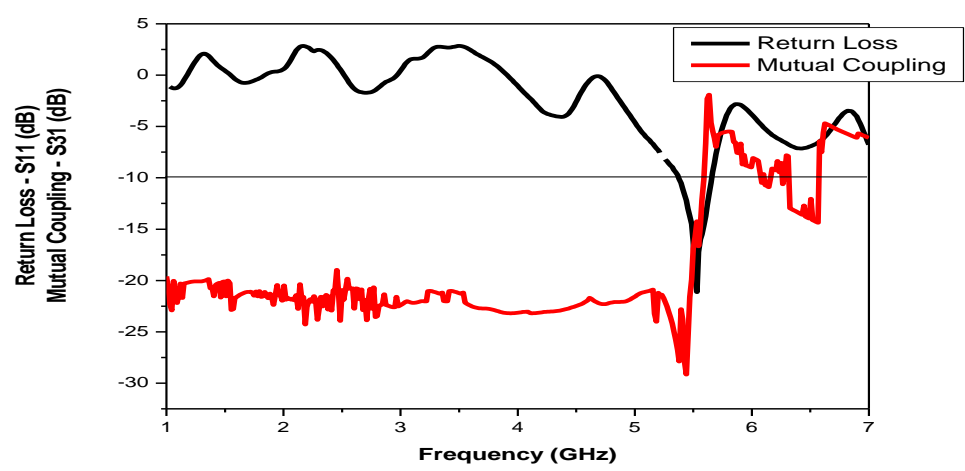

Fig. 22 - Graph of Return Loss and Mutual Coupling - S31versus Frequency of CMAA.

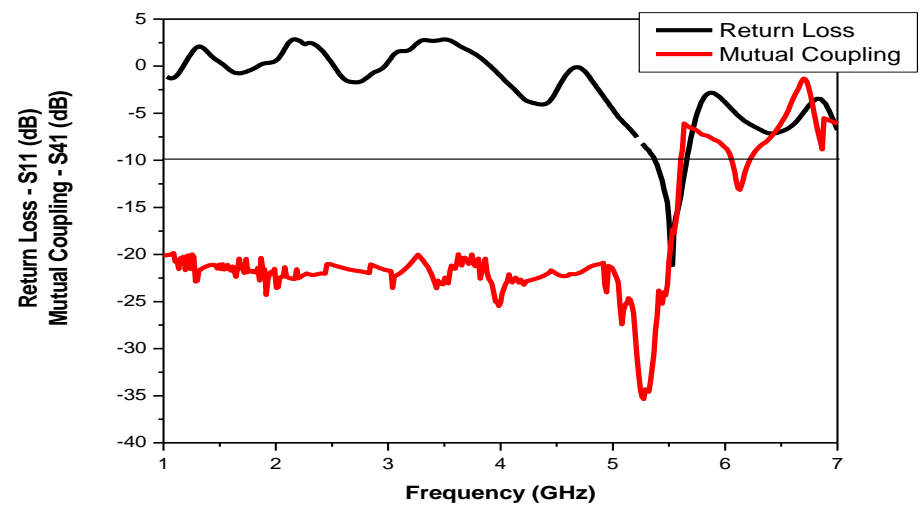

Fig. 23 - Graph of Return Loss and Mutual Coupling - S41versus Frequency of CMAA.

The graphs in Fig. 21, 22 and 23 show that CMAA is resonating at the fundamental frequency of $5.53 \mathrm{GHz}$. The return loss produced at the resonant frequency of $5.53 \mathrm{GHz}$ is equal to $-21.06 \mathrm{~dB}$. From the return loss graph the parameter bandwidth is calculated. The lower frequency is subtracted from upper frequency where the return loss is equal to $-10 \mathrm{~dB}$. The lower and upper frequencies are located on either side of the resonant frequency. Therefore the bandwidth of CMAA is equal to $273 \mathrm{MHz}$. The bandwidth (\%) is determined by using equation (1)

$$
\frac{\text { Bandwidth }}{\text { Resonant frequency }} \times 100 \%
$$


Hence CMAA is producing bandwidth of $4.89 \%$. As the bandwidth of CMAA is very narrow it is very much required to enhance it.

From Fig. 21, 22 and 23 we see that the measured values of mutual coupling $\left(S_{21}, S_{31}\right.$ and $\left.S_{41}\right)$ are $-16.95,-14.22$ and $-17.30 \mathrm{~dB}$ respectively. The values of mutual coupling are very high and need to be decreased. Additionally we can see that the graphs of return loss and mutual coupling versus frequency are crossing each other at the resonant frequency of $5.53 \mathrm{GHz}$. This means that there is interference between the transmitting element 1 and the receiving elements 2, 3 and 4 respectively. Hence there is no proper transmission and reception of information between the transmitting element 1 and the receiving elements 2,3 and 4.

The graphs of return loss and mutual coupling parameters versus frequency of proposed microstrip antenna array 1 are shown in Fig. 24, 25 and 26 respectively. From Fig. 24, we see that the return loss plot depicts that proposed microstrip antenna array 1 is resonating at 3.87, 5.53 and $6.74 \mathrm{GHz}$. The return losses obtained at these three resonant frequencies are $-18.83,-25.41$ and $-18.18 \mathrm{~dB}$. The bandwidth is determined by subtracting the lower frequency from the upper frequency where the return loss crosses the $-10 \mathrm{~dB}$ value. The calculated bandwidths at the three resonant frequencies are equal to 110,740 and $220 \mathrm{MHz}$. Hence the overall bandwidth of proposed microstrip antenna array 1 is equal to $19.48 \%$. This means that proposed microstrip antenna array 1 is a better antenna than CMAA in terms of bandwidth.

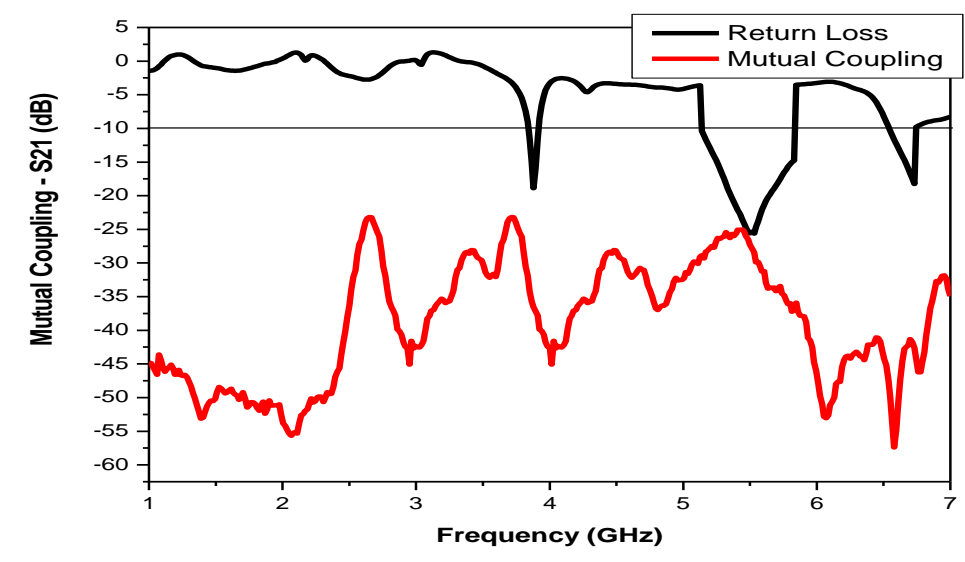

Fig. 24 - Graph of Return Loss and Mutual Coupling - S21versus Frequency of Proposed Microstrip Antenna Array 1.

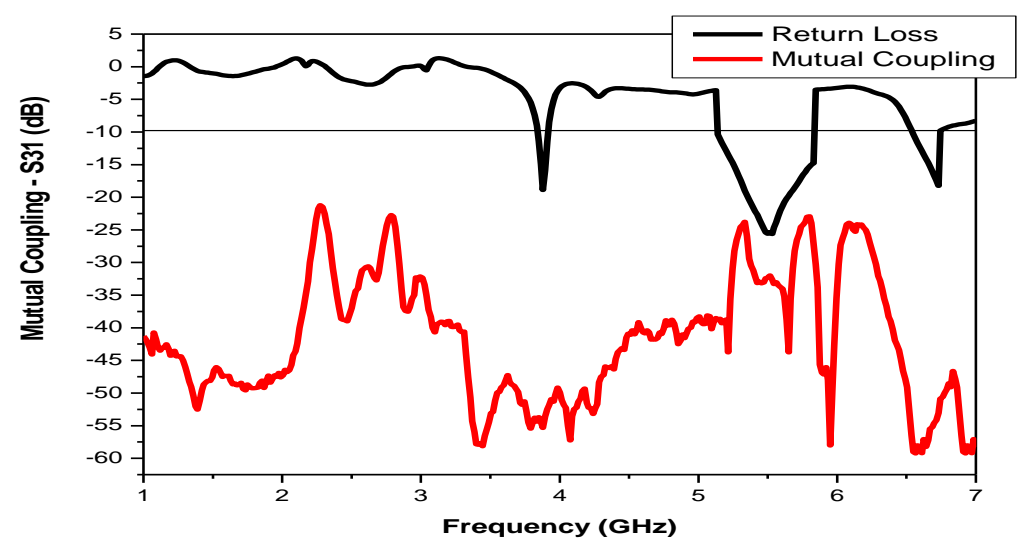

Fig. 25 - Graph of Return Loss and Mutual Coupling - S 31 versus Frequency of Proposed Microstrip Antenna Array 1. 


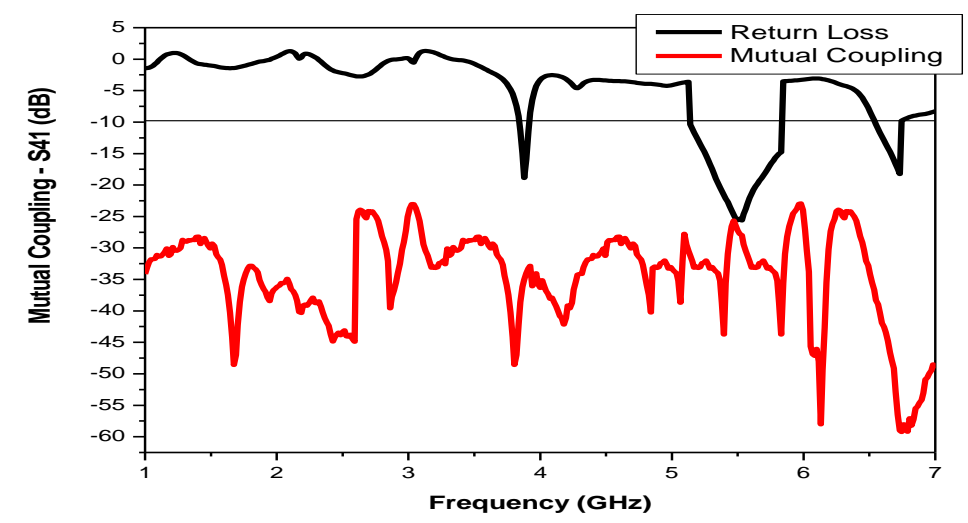

Fig. 26 - Graph of Return Loss and Mutual Coupling - S41versus Frequency of Proposed Microstrip Antenna Array 1.

The values of mutual coupling produced by proposed microstrip antenna array 1 at the resonant frequency of $5.53 \mathrm{GHz}$ are $-27.97,-28.44$ and $-31.61 \mathrm{~dB}$ respectively. The graphs of return loss and mutual coupling versus frequency depicted in Fig. 24, 25 and 26 are not crossing each other at the resonant frequency of 5.53 GHz. This means that interference between the transmitting element 1 and the receiving elements 2, 3 and 4 is reduced. Hence proposed microstrip antenna array 1 is a better antenna than CMAA in terms of mutual coupling.

The graphs of return loss and mutual coupling parameters versus frequency of proposed microstrip antenna array 2 are shown in Fig. 27, 28 and 29 respectively. From Fig. 27, we see that the return loss plot depicts that proposed microstrip antenna array 2 is resonating at 4.05 and $5.53 \mathrm{GHz}$. The return losses obtained at these two resonant frequencies are -19.11 and $-25.83 \mathrm{~dB}$. The calculated bandwidths at the two resonant frequencies are equal to 2130 and $1140 \mathrm{MHz}$. Hence the overall bandwidth of proposed microstrip antenna array 2 is equal to $75.91 \%$.

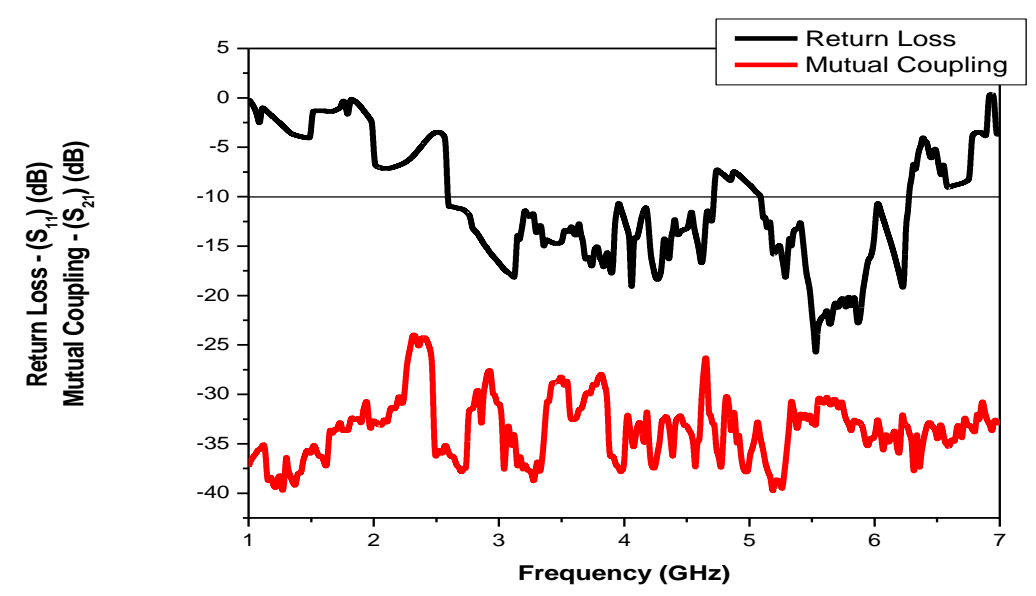

Fig. 27 - Graph of Return Loss and Mutual Coupling - S21versus Frequency of Proposed Microstrip Antenna Array 2. 


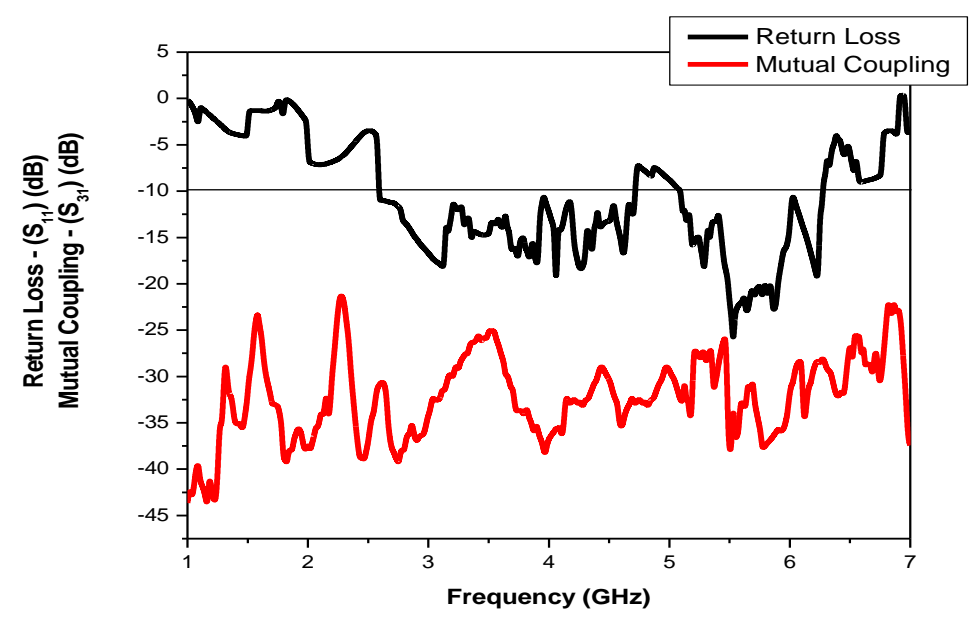

Fig. 28 - Graph of Return Loss and Mutual Coupling - S 31 versus Frequency of Proposed Microstrip Antenna Array 2.

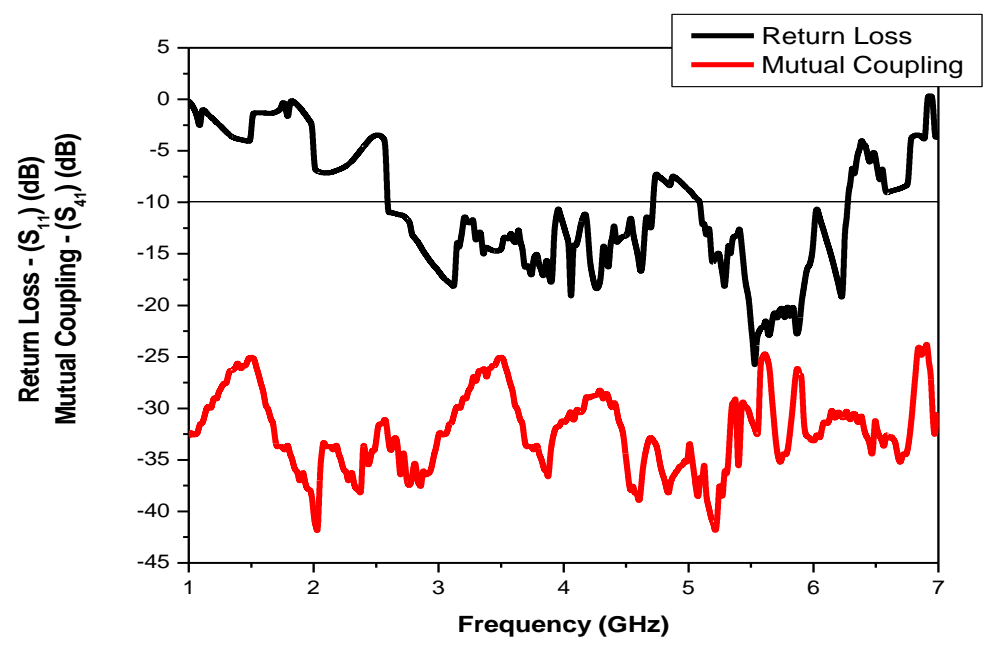

Fig. 29 - Graph of Return Loss and Mutual Coupling - S41versus Frequency of Proposed Microstrip Antenna Array 2.

The values of mutual coupling produced by proposed microstrip antenna array 2 at the resonant frequency of 5 $.53 \mathrm{GHz}$ are $-33.81,-32.17$ and $-31.95 \mathrm{~dB}$ respectively. The graphs of return loss and mutual coupling versus frequency depicted in Figs. 27, 28 and 29 are not crossing each other at the resonant frequency of $5.53 \mathrm{GHz}$. This means that interference between the transmitting element 1 and the receiving elements 2,3 and 4 is reduced.

Comparing the performances of proposed microstrip antenna arrays 1 and 2 we see that proposed microstrip antenna array 2 is producing enhanced overall bandwidth of $75.91 \%$ compared to $19.48 \%$ of proposed microstrip antenna array 1 . Moreover, the reduction in mutual coupling in proposed microstrip antenna array 2 is better than that produced due to proposed microstrip antenna array 1 . Hence proposed microstrip antenna array 2 is performing better than proposed microstrip antenna array 1 in terms of bandwidth and mutual coupling.

Fig. 30, 31 and 32 depict the graphs of return loss and mutual coupling versus frequency of the proposed microstrip antenna array 3. 


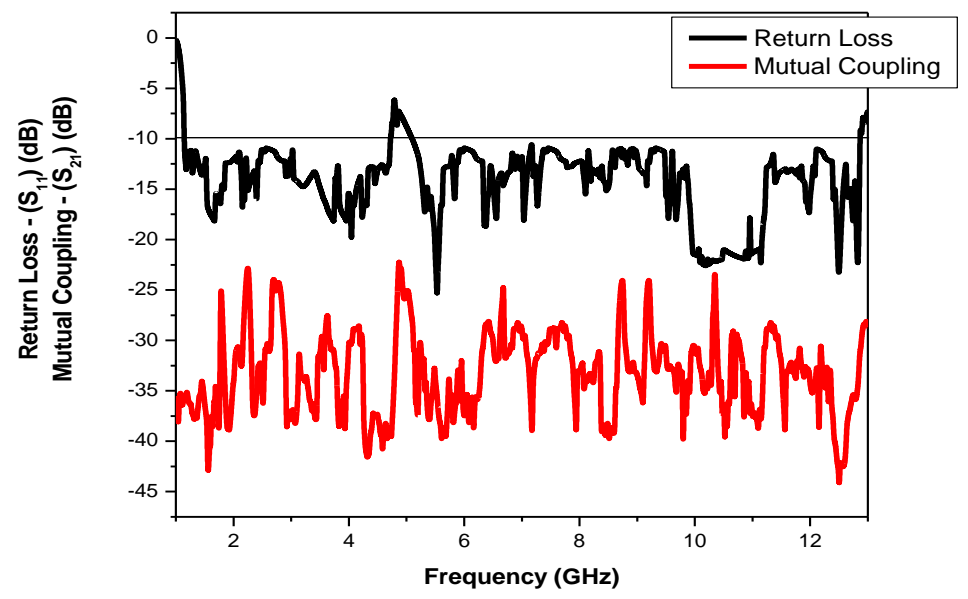

Fig. 30 - Graph of Return Loss and Mutual Coupling - $\mathbf{S}_{21}$ versus Frequency of Proposed Microstrip Antenna Array 3.

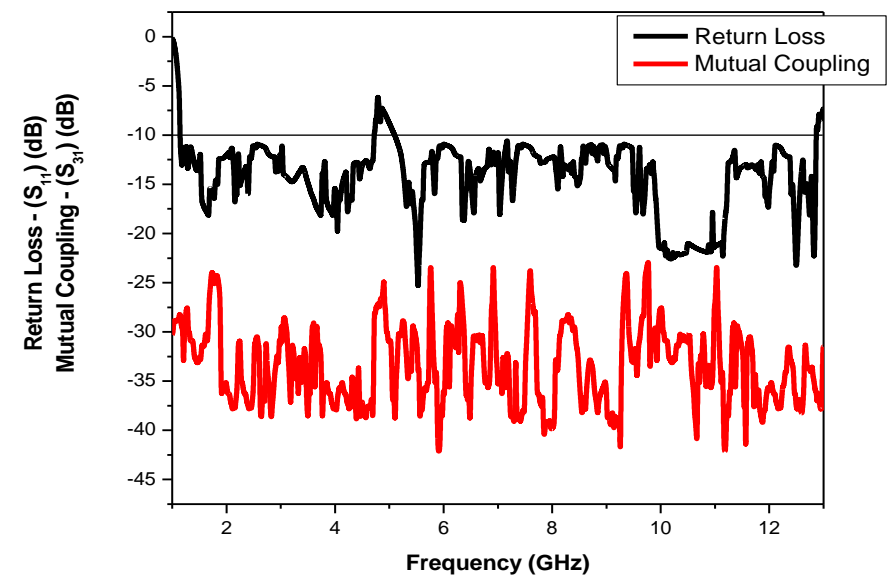

Fig. 31 - Graph of Return Loss and Mutual Coupling - S $\mathbf{3}_{31}$ versus Frequency of Proposed Microstrip Antenna Array 3.

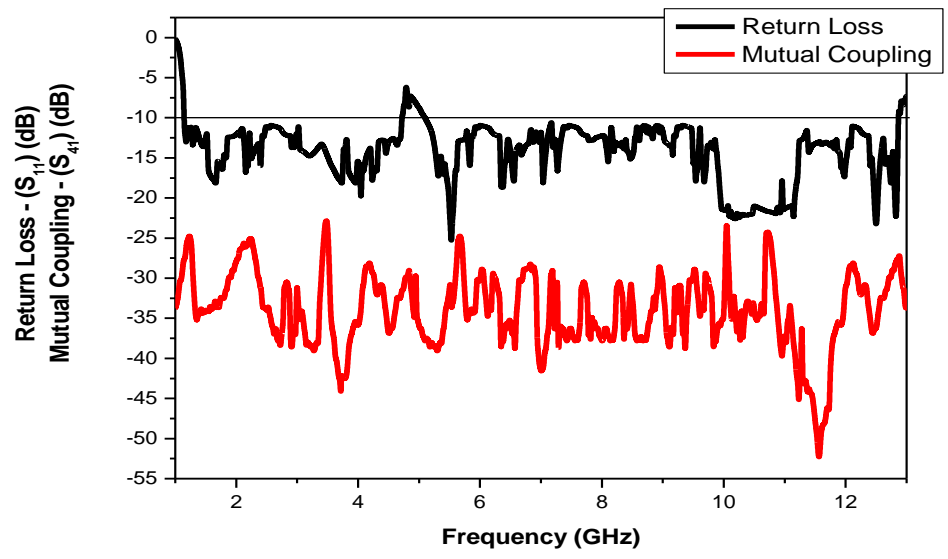

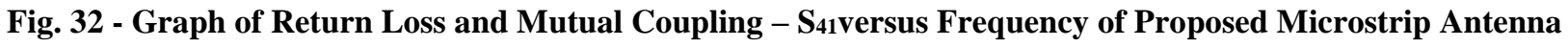
Array 3. 
From Fig. 30, the return loss plot shows that the proposed microstrip antenna array 3 is resonating at fundamental frequency of $4.05 \mathrm{GHz}$. It is also resonating at $5.53 \mathrm{GHz}$. The return loss at the resonant frequency of $5.53 \mathrm{GHz}$ is $-26.12 \mathrm{~dB}$. The return loss produced in the absence of silver coating at the resonant frequency of $5.53 \mathrm{GHz}$ is $-23.34 \mathrm{~dB}$ as depicted in Fig. 27. As the return loss of proposed microstrip antenna array 3 is lesser than that of proposed microstrip antenna array 2, proposed microstrip antenna array 3 provides better matching compared to proposed microstrip antenna array 2 . Hence the former antenna is better than the latter in terms of return loss.

The bandwidths produced by proposed microstrip antenna array 3 at the corresponding resonant frequencies are 3.5 and $7.6 \mathrm{GHz}$ respectively. Therefore, the overall bandwidth is equal to $228.54 \%$. The overall bandwidth (\%) of proposed microstrip antenna 3 is greater than that of proposed microstrip antenna array 2 equal to $75.91 \%$. The values of mutual coupling measured at the resonant frequency of $5.53 \mathrm{GHz}$ are equal to are $-35.57,-34.95$ and $-34.42 \mathrm{~dB}$ respectively as depicted in Figs.30, 31 and 32 respectively. The values of mutual coupling of proposed microstrip antenna array 3 are lesser than that of proposed microstrip antenna array 2. Hence with the introduction of silver of nano thickness $30 \mathrm{~nm}$, mutual coupling between the antenna elements is reduced. There is no overlap of return loss and mutual coupling plots of proposed microstrip antenna array 3. Hence there is better transmission and reception of information between the transmitting element 1 and the receiving elements 2, 3 and 4 of proposed microstrip antenna array 3 . Hence proposed microstrip antenna array 3 is a better antenna than proposed microstrip antenna array 2 in terms of return loss, bandwidth and mutual coupling.

Fig. 33 shows the radiation plots of CMAA, proposed microstrip antenna arrays 2 and 3. The microstrip antenna arrays are compared in terms of desired power or forward power, undesired power or backward power and front to back ratio (FBR). The forward power is measured at the angle of $90^{\circ}$ and the backward power at the angle of $270^{\circ}$.

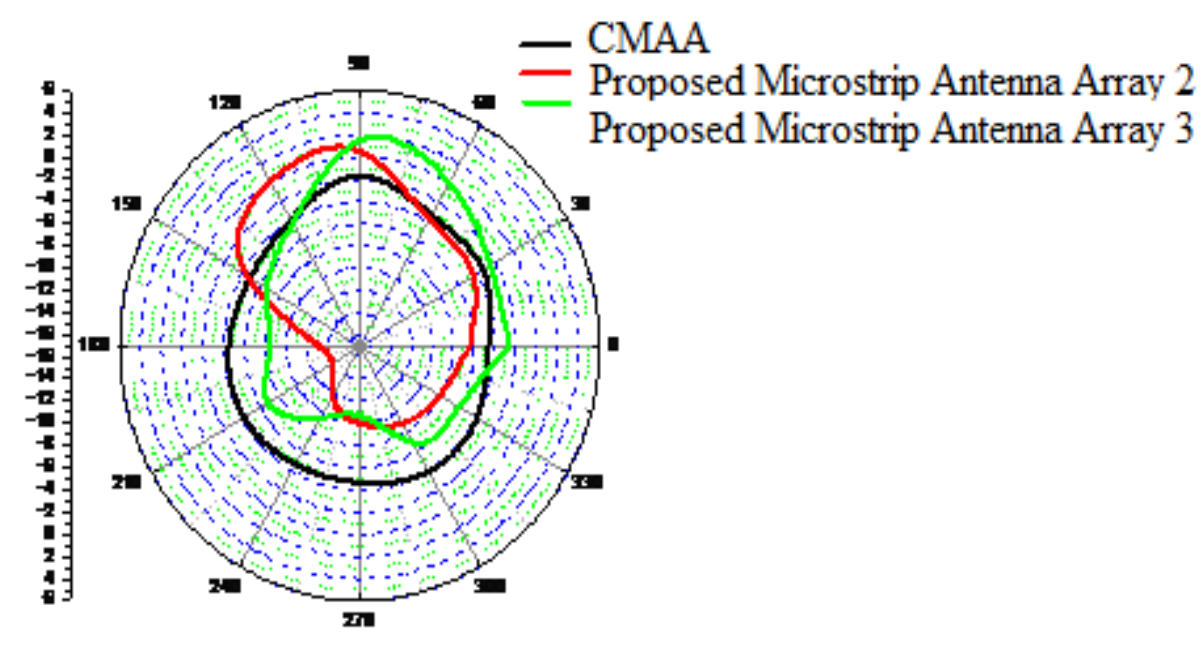

Fig. 33 - Radiation Plot of CMAA, Proposed Microstrip Antenna Array 2 and Proposed Microstrip Antenna Array 3.

From Fig. 33, we see that proposed microstrip antenna arrays 2 and 3 are radiating forward powers equal to 0.5 and $1 \mathrm{~dB}$ respectively. More power equal to $1 \mathrm{~dB}$ is being radiated by the proposed microstrip antenna array 3 compared to $0.5 \mathrm{~dB}$ by proposed microstrip antenna array 2. Hence the proposed microstrip antenna array 3 is a better radiator compared to proposed microstrip antenna array 2 in the desired direction or forward direction. As far as the back lobe radiation is concerned, the proposed microstrip antenna arrays 2 and 3 are radiating backward power of -9 and $-9.5 \mathrm{~dB}$ respectively. In the undesired direction as well, the proposed microstrip antenna array 3 is the better antenna compared to its counterpart because it is radiating the lesser power of $-9.5 \mathrm{~dB}$ as compared to $-9 \mathrm{~dB}$. The parameter Front to Back ratio (FBR) is calculated by deducting the undesired power from the desired power. The FBR values of proposed microstrip antenna arrays 2 and 3 are 9.5 and $10.5 \mathrm{~dB}$ respectively. The proposed microstrip antenna array 3 has greater value of FBR compared to that of proposed microstrip antenna array 2.

Comparing the performances of proposed microstrip antenna arrays 2 and 3 we see that the latter antenna has enhanced bandwidth $(\%)$ and is producing better reduction in mutual coupling than the former antenna. The latter antenna has surpassed the former candidate in terms of radiation properties - back lobe power, forward power and FBR. Hence proposed microstrip antenna array 3 is a better candidate than proposed microstrip antenna array 2 . Hence the proposed microstrip antenna array with silver coating is performing better than the proposed microstrip antenna array without silver deposition. Silver is so special compared to other metals because silver has the highest electrical 
conductivity. As to why silver is the best conductor is based on fermi sphere surface area. The conductivity in metals as per quantum free electron theory depends on Fermi sphere surface area. The Fermi sphere for any material can be plotted by taking the magnitude of Fermi velocity and radius of Fermi sphere. Mean free path is temperature dependent and Fermi velocity is temperature independent. Hence the ratio of mean free path and Fermi velocity is not constant. For silver Fermi sphere surface are is more than that of other metals.

To summarize in the first step performance of CMAA design is improved by loading fork shape slot type EBG structure in the ground plane. In the second step U shape patch type EBG structure is incorporated on the surface and in between the radiating patches with fork shape slot type EBG structure in the ground plane to obtain good bandwidth and appreciable decrease in mutual coupling. This design also demonstrates good radiation characteristics in terms of back lobe reduction and greater for ward power. In the final step silver metal is deposited on top of the entire copper to investigate the further performance. The motivation behind the design improvement is the ability of EBG structures and silver coating deposition. Table 2 benchmarks the proposed design with existing literature.

Table 2 - Comparison of proposed design with exiting literature.

\begin{tabular}{|c|c|}
\hline & Performance Parameters \\
\hline $\begin{array}{c}\text { Ref [5] (Star slot EBG) } \\
\text { Ref [6] }\end{array}$ & $\begin{array}{c}\text { Bandwidth }=5 \% \text {, Mutual Coupling }=-30 \mathrm{~dB} \\
\text { Mutual Coupling }=-35 \mathrm{~dB}\end{array}$ \\
\hline $\operatorname{Ref}[7]$ & $\begin{aligned} \text { Bandwidth }= & 37 \text { and } 58 \%, \text { Mutual Coupling }= \\
& -14.6 \text { and }-20.2 \mathrm{~dB} .\end{aligned}$ \\
\hline Ref [8] & Bandwidth $=3.6 \mathrm{GHz}$ \\
\hline Ref [9] & $\begin{array}{c}\text { Bandwidth }=2 \mathrm{GHz} \text {, Mutual Coupling }=-13 \text { to } \\
-15 \mathrm{~dB} .\end{array}$ \\
\hline Ref [10] & $\begin{array}{c}\text { Bandwidth }=5.1 \mathrm{GHz} . \text { Reduction in mutual } \\
\text { coupling observed. }\end{array}$ \\
\hline $\operatorname{Ref}[11]$ & Mutual Coupling $=-47.23 \mathrm{~dB}$ \\
\hline Ref [12] & Mutual Coupling reduced by $5.5 \mathrm{~dB}$. \\
\hline Ref [13] & Increase in bandwidth observed. \\
\hline $\operatorname{Ref}[14]$ & Mutual Coupling $=-23.5 \mathrm{~dB}$ \\
\hline Ref [15] & $\begin{array}{c}\text { Bandwidth }=5.7 \text { and } 4.3 \% \text {, Mutual Coupling }= \\
-20 \mathrm{~dB} .\end{array}$ \\
\hline Proposed Design & $\begin{array}{c}\text { Bandwidth }=228.54 \% . \text { Mutual Coupling }= \\
-35.57,-34.95 \text { and }-34.42 \mathrm{~dB}\end{array}$ \\
\hline
\end{tabular}

\section{Conclusion}

The four element microstrip antenna array with silver metal coating is designed and tested experimentally. In this paper, four element microstrip patch antenna array with silver material of thickness $30 \mathrm{~nm}$ is performing better than that without the silver deposition. A predominant improvement in overall bandwidth of 228.54 (\%) is obtained. Appreciable decrease in mutual coupling coefficients is obtained. The deposition of silver material is thus leading to good radiation characteristics with decrease in back lobe radiation and increase in forward power. This reflects the importance of nanotechnology in enhancing the performance characteristics of microstrip antenna array.

\section{Acknowledgement}

The authors would like to thank to Gulbarga University for the support provided in this study.

\section{References}

[1] Constantine Balanis, A. (1997). Antenna theory analysis and design (2 ${ }^{\text {nd }}$ ed.). John Wiley \& Son, Inc.

[2] Bahl, I.J., \& Bhartia, P. (1980). Microstrip antennas (3rd ed.). Artech House.

[3] James Scott. (1979). Lecture notes of EEET 1071/1127 microwave and wireless passive circuit design.

[4] Fan Yang., \& Yahya Rahmat-Sanii. (2009). Electromagnetic band gap structures in antenna engineering. Cambridge University Press. 
[5] Elsheak, D.N.; Abdullah, E.A.; Iskander, M.F.; \& Elsadek, H.A. (2010). Microstrip antenna array with 2Delectromagnetic band gap structure shapes to reduce harmonics and mutual coupling. Progress in Electromagnetic Research C, 12, 203-213.

[6] Rajasekhar, A.; \& Varaprasad, K. (2017). Mutual coupling reduction of microstrip antenna array by using the electromagnetic band gap structures. International Research Journal of Engineering and Technology, 04, 19881993.

[7] Mohamed I, Ahmed.; Sebak, A. A.; Esmat A, Abdallah.; \& Hadia M. Elhennnawy. (2014). UWB KSA sign shape slot microstrip antenna array mutual coupling reduction for official applications. IACSIT International Journal of Engineering and Technology, 6, 513- 519.

[8] Nagendra, Kushwaha.; \& Raj, Kumar. (2014). Study of different electromagnetic band gap (EBG) structures for single and dual band applications. Journal of Microwaves, Optoelectronics and Electromagnetic Applications, 13, 16-30.

[9] Kiarash, Malekzadeh.; \& Mohamad, Soleimani. (2016). Design, optimization and improvement of an aperture coupled stack microstrip antenna array using an electromagnetic band gap structure. Proc. of the $4^{\text {th }}$ Iranian Conference on Electrical and Electronic Engineering (ICEEE - 2012).

[10] Huda Sh, Gally.; Zeki A, Ahmed; \& Ahmad H, Abood. (2018). Surface wave minimizing in $2 \times 2$ microstrip antenna array. Journal of Natural Sciences Research, 08, 67-73.

[11] Vasu Babu, K.; Anuradha, B.; \& Chandra Bhushana Rao, K. (2016). Reduction of mutual coupling by desegregated EBG structure for microstrip antenna array radar applications. Proc. of the International Conference on Signal Processing, Communication, Power and Embedded System (SCOPES - 2016).

[12] Dhamankar, S.; \& Lopes, S. (2016). Mutual coupling reduction techniques in microstrip patch antennas: survey. International Research Journal of Engineering and Technology, 3, 1064-1069.

[13] Naresh Kumar, Poonia.; \& Krishan Kumar, Sherdia. (2013). Microstrip antenna array for WiMax and WLAN applications. International Journal of Advanced Research in Computer and Communication Engineering, 2,3437 3440 .

[14] Shaban, H.F.; Elmikaty, H.A.; \& Shaalan, A.A. (2008). Study the effects of electromagnetic band-gap (EBG) substrate on two patches microstrip antenna. Progress in Electromagnetic Research B, 10, 55-74.

[15] Duong Thi Thanh Tu, Nguyen Van, Hoc.; Pham Dinh, Son.; \& Vu Van, Yem. (2017). Design and implementation of dual-band MIMO antenna with low mutual coupling using electromagnetic band gap structures for portable equipments. International Journal of Engineering and Technology Innovation, 07, 48-60. 